\title{
Slit2 expression and its correlation with subcellular localization of $\beta$-catenin in gastric cancer
}

\author{
RONGLIANG SHI ${ }^{1}$, WEIYAN LIU ${ }^{1}$, BINGYA LIU $^{2}$, ZIPING XU $^{1}$, LIPING CHEN $^{1}$ and ZIPING ZHANG ${ }^{1}$ \\ ${ }^{1}$ Department of General Surgery, Central Hospital of Shanghai Minhang District, Shanghai 201100; \\ ${ }^{2}$ Department of General Surgery, Shanghai Institute of Digestive Surgery, Ruijin Hospital, \\ Shanghai Jiao Tong University, School of Medicine, Shanghai 200025, P.R. China
}

Received June 10, 2013; Accepted July 4, 2013

DOI: $10.3892 /$ or.2013.2662

\begin{abstract}
Gastric cancer is the fourth most common cancer worldwide. Several signaling pathways are involved in gastric cancer development and progression. Slit 2 was recently found to be involved in cancer; however, its expression pattern in gastric cancer has not been discovered yet. In the present study, we investigated the expression of Slit 2 in human gastric cancer and its correlation with the expression and subcellular localization of $\beta$-catenin. Immunohistochemistry (IHC) staining revealed that Slit 2 was highly expressed in human gastric cancer tissues, while it was low or weakly expressed in normal gastric tissues. The differences in clinicopathological features between different groups were determined using Pearson's $\chi^{2}$ test. Slit2 levels were significantly associated with differentiation, Lauren's classification, lymph node metastasis and TNM staging. Slit2 levels were positively correlated with $\beta$-catenin level in gastric cancer tissues and cell lines. High levels of Slit2 were correlated with the membrane localization of $\beta$-catenin, and low levels of Slit 2 were correlated with nuclear translocation of $\beta$-catenin in both gastric cancer tissues and cell lines assayed by IHC and immunofluorescence staining, respectively. Our data suggest that Slit2 was highly expressed in gastric cancer patients with less advanced clinicopathological features. Slit2 levels were correlated with $\beta$-catenin level and subcellular localization.
\end{abstract}

\section{Introduction}

Gastric cancer is the fourth most common cancer worldwide and is the second most common causes of cancer-related mortality; it also has a poor prognosis (1). Although the 5-year survival rate in patients with early-stage disease is $\sim 90 \%$, since the vast majority present with distant metastasis, the overall 5 -year survival rate is typically $<20 \%$ (2). Patients 5-year

Correspondence to: Dr Ziping Zhang, Department of General Surgery, Central Hospital of Shanghai Minhang District, 170 Xinsong Road, Shanghai 201100, P.R. China

E-mail: roundshi@gmail.com

Key words: Slit2, $\beta$-catenin, gastric cancer, clinical significance survival rate has also been significantly correlated with the degree of tumor invasion, the presence of lymph node and/or distant metastases and the TNM stage $(3,4)$. However, only a limited number of molecules that have clinicopathological significance in gastric cancer have been discovered.

To date, several mechanisms that drive gastric cancer development and progression have been discovered. Wnt/ $\beta$ catenin signaling is a well-known signaling pathway that is activated and is critical in gastric cancer development and progression. The Slit family of proteins were identified as conserved targets of the Wnt/ $\beta$-catenin signaling pathway (5). Slit2 is a secretory glycoprotein and a ligand in the Slit/Robo system (6). The physiological function of Slit2 is to maintain the development of the neural system (7). Slit2 is responsible for guiding neural cell migration by preventing inappropriate midline axonal crossing events (8). Recently, Slit2 was found to contribute to gut development (9). Slit2 protein was located in the outer gut mesenchyme in regions that partially overlap with the secretion of netrin-1. Functionally, vagal sensory axons are responsive to Slit proteins and are thus repelled by Slits secreted in the gut wall and are prevented from reaching inappropriate targets (9).

The discovery of Slit 2 as a guidance cue across multiple tissue types has prompted a number of studies to examine its potential as a biomarker for cancer, with two contrasting roles for Slit2 having been proposed; some suggest that it functions as a tumor suppressor, whereas others propose that it plays a role in oncogenesis. One of the mechanisms that support Slit2 as a tumor suppressor is that Slit2 promoter is hypermethylated in several types of human cancer. This methylation is found in many types of malignancies including cervix cancer (10), ovarian cancer (11), breast cancer (12), hepatocellular cancer (13), colon cancer (14), lung cancer (14) and leukemia (15). On the other hand, Slit2 is found to be prooncogenic. This notion is supported by the evidence that link Slit2 expression to enhanced malignancy. Accordingly, the clinical significance of Slit2 levels is highly case-dependent. Loss of Slit2 was found to be associated with poor survival in cervical cancer patients (16). Conversely, the findings that Slit2 levels were higher in tumors of patients with recurrent endometrial cancer compared to those without recurrence supported its role as a recurrence biomarker for endometrial cancer $(17,18)$. 
Mechanically, Slit2 regulates several signaling pathways involved in cell growth and metastasis. During breast development, Slit2 limits basal cell proliferation by inhibiting canonical Wnt/ $\beta$-catenin signaling, increasing the cytoplasmic and membrane pools of $\beta$-catenin at the expense of its nuclear pool (5). Hence, Slit2 may mediate its function through modulating $\beta$-catenin signaling. In cancer, it was reported that Slit2 suppressed $\beta$-catenin activity in breast cancer (19). It remains unknown whether this correlation is applied to gastric cancer. Other signaling pathways or molecules are AKT/GSK3 $\beta$ (20), RhoA (21) and frizzled (22). Slit2 is a multi-functional molecule and may play different roles in malignant and nonmalignant cells.

Despite the inconsistency between studies on Slit2, its expression pattern and clinical significance in gastric cancer remain unknown. Hence, we examined the expression pattern and clinical correlations of Slit2 in human gastric cancer.

\section{Materials and methods}

Immunohistochemistry (IHC). Gastric cancer tissues, confirmed by pathological diagnosis, were obtained from 89 patients who underwent radical resection for gastric cancer between 2006 and 2008 at the Department of Surgery, Central Hospital of Shanghai Minhang District, Shanghai, China. The corresponding non-tumor gastric tissues were obtained at least $6 \mathrm{~cm}$ from the tumor. All tissue samples were formalin-fixed and paraffin-embedded. TNM staging was classified based on the criteria of the American Joint Committee on Cancer (AJCC, 7th edition) for gastric cancer. The study was approved by the Shanghai Jiaotong University Medical School Institutional review board.

IHC staining was performed by using a highly sensitive streptavidin-biotin-peroxidase detection system with gastric cancer tissue microarrays. Rabbit monoclonal anti-Slit2 (working dilution 1:100) was purchased from Epitomics (Burlingame, CA, USA) and rabbit anti- $\beta$-catenin (working dilution 1:100) was purchased from Cell Signaling Technology (Danvers, MA, USA). Immunolabeling was conducted using Dako EnVision + Rabbit Polymer (cat. no. K4003) from Dako (Carpinteria, CA, USA). The slides were counterstained with hematoxylin and coverslipped.

IHC scoring. The histology of the samples was examined by two histopathologists independently without knowledge of clinicopathological information. We scored the slides according to a previous publication (23). The percentage of positive tumor cells was assigned to 5 categories: $\leq 5 \%(0)$, $5-25 \%$ (1), $25-50 \%$ (2), $50-75 \%$ (3), and $\geq 75 \%$ (4). Positive cells $(\leq 5 \%)$ were used as the cut-off to define negative tumors. The intensity of immunostaining was scored as: weak (1), moderate (2), and strong (3). The percentage of positivity of tumor cells and staining intensity were multiplied to produce a weighted score for each tumor specimen. The intensity scores were grouped as low (which included scores 0 to +4 ) and high (which included scores +6 and +12 ).

Cell culture. Human gastric cancer cell lines SGC-7901, MKN28, MKN45, and immortalized human gastric epithelial cell line GES-1, were obtained from the Shanghai Institute
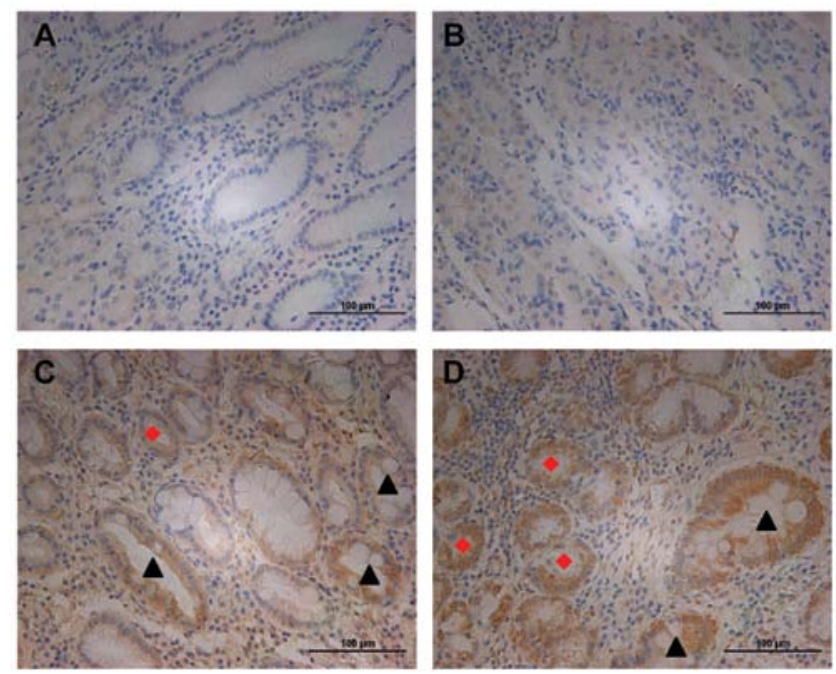

Figure 1. Expression of Slit2 in human non-tumoral gastric tissues Immunohistochemistry staining of Slit 2 protein in normal gastric tissues (A and B), as well as precancerous lesions (C and D). Intestinal metaplasia (IM) is indicated by black arrow heads. Dysplasia glands are indicated by red diamonds. Original magnification, x200.

of Cell Biology, Chinese Academy of Sciences. KATO-III, SNU-16, NCI-N87 and AGS were obtained from the American Type Culture Collection. The cells were grown in RPMI-1640 medium containing $10 \%$ fetal bovine serum (FBS), penicillin and streptomycin (Gibco-BRL, Gaithersburgh, MD, USA).

Western blotting. Whole cell lysates were harvested using RIPA cell lysis buffer supplemented with a protease inhibitor cocktail (Sigma). A total of $50 \mu \mathrm{g}$ protein was separated by SDS polyacrylamide gel electrophoresis and blotted onto $0.22-\mu \mathrm{m}$ polyvinylidene difluoride membranes (Millipore, Billerica, MA, USA). Antibodies against Slit2 (Epitomics) were used at 1:1,000 dilutions. Antibodies against GAPDH (Sigma) were used at a 1:5,000 dilution. The signals were visualized using Li-COR Odyssey Sa model 9260 (Li-COR Corp., Lincoln, NE, USA) and images were captured and managed using Odyssey Sa Infrared Image System (Li-COR Corp.). Relative density of Slit 2 or $\beta$-catenin was measured by the following equation: Relative density $=$ density of Slit 2 or $\beta$-catenin band/density of GAPDH.

Immunofluorescence staining. Cells were fixed with $4 \%$ formaldehyde and then permeabilized with PBS containing $0.2 \%$ Triton X-100. Slides were blocked by 5\% BSA and incubated with a primary antibody at room temperature for $1 \mathrm{~h}$ followed by TRITC-labeled goat anti-rabbit IgG (Sigma, St. Louis, MO, USA) for an additional hour. Nuclei were counterstained using DAPI (Molecular Probes). Slides were washed by PBS, mounted and observed under a microscope. Immunofluorescence staining was visualized using an Olympus BX50 microscope (Olympus Opticol Co., Tokyo, Japan), images were captured using Nikon Digital Sight DS-U2 (Nikon, Tokyo, Japan) and NIS-Elements F3.0 software was used (Nikon).

Statistical analysis. For IHC staining, the differences in clinicopathological features between the different groups were determined using Pearson's $\chi^{2}$ test. $\mathrm{P}<0.05$ was considered to 


\begin{tabular}{|c|c|c|c|c|c|c|}
\hline \multirow{3}{*}{$\begin{array}{l}\text { Concept type by cancer } \\
\text { Bladder Cancer }\end{array}$} & \multirow{2}{*}{\multicolumn{2}{|c|}{$\begin{array}{c}\text { Cancer } \\
\text { vs. } \\
\text { Normal }\end{array}$}} & \multicolumn{4}{|c|}{ Cancer vs. Cancer } \\
\hline & & & \multicolumn{2}{|c|}{ 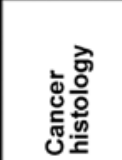 } & \multicolumn{2}{|c|}{ 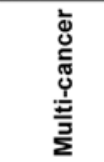 } \\
\hline & & 8 & 5 & 5 & & 4 \\
\hline Brain and CNS Cancer & 2 & 3 & 10 & 8 & 7 & \\
\hline Breast Cancer & 2 & 27 & 22 & 18 & 1 & 3 \\
\hline Cervical Cancer & & 3 & 3 & 4 & & 3 \\
\hline Colorectal Cancer & 1 & 16 & 5 & 6 & & 13 \\
\hline Esophageal Cancer & 3 & & 2 & 2 & & 4 \\
\hline$\rightarrow$ Castric Cancer & 2 & & 6 & 5 & 1 & 3 \\
\hline Head and Neck Cancer & 1 & 13 & 2 & 3 & & \\
\hline Kidney Cancer & 2 & 7 & 9 & 10 & 6 & \\
\hline Leukemia & 3 & 1 & 3 & 5 & & 7 \\
\hline Liver Cancer & 3 & 4 & 3 & 3 & 1 & 2 \\
\hline Lung Cancer & & 16 & 6 & 6 & 4 & \\
\hline Lymphoma & 8 & & 7 & 9 & & 7 \\
\hline Melanoma & & 2 & 1 & 1 & 6 & \\
\hline Myeloma & 1 & 1 & 2 & 2 & & 3 \\
\hline Other Cancer & 3 & 8 & 3 & 7 & 2 & 1 \\
\hline Ovarian Cancer & & & 11 & 8 & & 1 \\
\hline Pancreatic Cancer & 3 & 1 & & & 3 & 4 \\
\hline Prostate Cancer & 1 & 11 & 2 & 2 & 2 & 2 \\
\hline Sarcoma & 4 & 8 & 28 & 24 & 6 & \\
\hline Significant unique concepts & 38 & 140 & 127 & 126 & 35 & 53 \\
\hline
\end{tabular}

Figure 2. Expression of Slit2 in multiply types of human cancer. A summary of Slit2 expression in multiply types of human cancer and normal counterparts are shown. Numbers represent the number of datasets with statistical significance. Data were analyzed using a publicly available database (www. oncomine.org). $\mathrm{H}$, overexpressed; L, underexpressed.

indicate a statistically significant result. Statistical Package for the Social Sciences version 13.0 (SPSS, Inc., Chicago, IL, USA) was used for all statistical analyses.

\section{Results}

Expression of Slit2 in non-tumor gastric tissues. We first examined the expression of Slit2 in human non-tumor gastric tissues. Slit2 did not express or was weakly expressed in normal gastric epithelial cells (Fig. 1A and B). However, we observed moderate staining of Slit2 in intestinal metaplasia (IM) (indicated by black arrow heads) and dysplasia glands (indicated by red diamonds) (Fig. 1A, C and D), two types of precancerous lesions, suggesting its role in early gastric tumorigenesis. These data suggested that Slit2 was not or was weakly expressed in normal gastric tissues.

Expression of Slit 2 in gastric cancer tissues. We first discovered that Slit2 mRNA was upregulated in gastric cancer tissues compared to normal gastric tissues analyzed using publicly available datasets from the Oncomine database (Fig. 2; indicated by arrow). We then investigated the expression of Slit2 protein in human gastric cancer tissues. The patients and pathological features of gastric cancer tissues are described in Table I. In 89 cases, 14.5\% (14/89) of cases were Slit2 negative
Table I. Patients and tumor characteristics.

\begin{tabular}{lc}
\hline Characteristics & $\mathrm{N}$ \\
\hline Gender & 23 \\
Female & 66 \\
Male & \\
Age (years) & \\
Female (range) & $66.04 \pm 12.0(34-83)$ \\
Male (range) & $65.27 \pm 10.3(45-83)$ \\
Differentiation & \\
High & 21 \\
Median & 24 \\
Low & 44 \\
Lauren's classification & \\
Intestinal & 53 \\
Diffuse & 36
\end{tabular}

T stage

T1

$\mathrm{T} 2$ 8

T3

T4

$\mathrm{N}$ stage

No

N1

N2

26

N3a

N3b

M stage

M0

86

M1

TNM (AJCC)

I-A

I-B

II-A

II-B

III-A

III-B

III-C

IV

(including 8 cases with no staining signal, 6 cases with staining cells $\leq 5 \%$ and staining intensity scored 1 ), while the remaining $85.5 \%(75 / 89)$ showed variable levels of Slit2 expression, with a medium-score of 4 . The strong and weak staining of Slit2 in intestinal-type (Fig. 3A) and diffuse-type (Fig. 3B) of gastric cancer tissues were shown at the cell membrane and cytoplasm.

The clinicopathological features of Slit2 in gastric cancer tissues were also examined. All the cases were divided into two groups according to the medium-score of Slit2; 44 cases were considered as weakly (IHC score $0-4$ ) and 45 cases were considered as strongly (IHC score 6-12) expressed Slit2. As shown in Table II, Slit2 level decreased from well-differenti- 

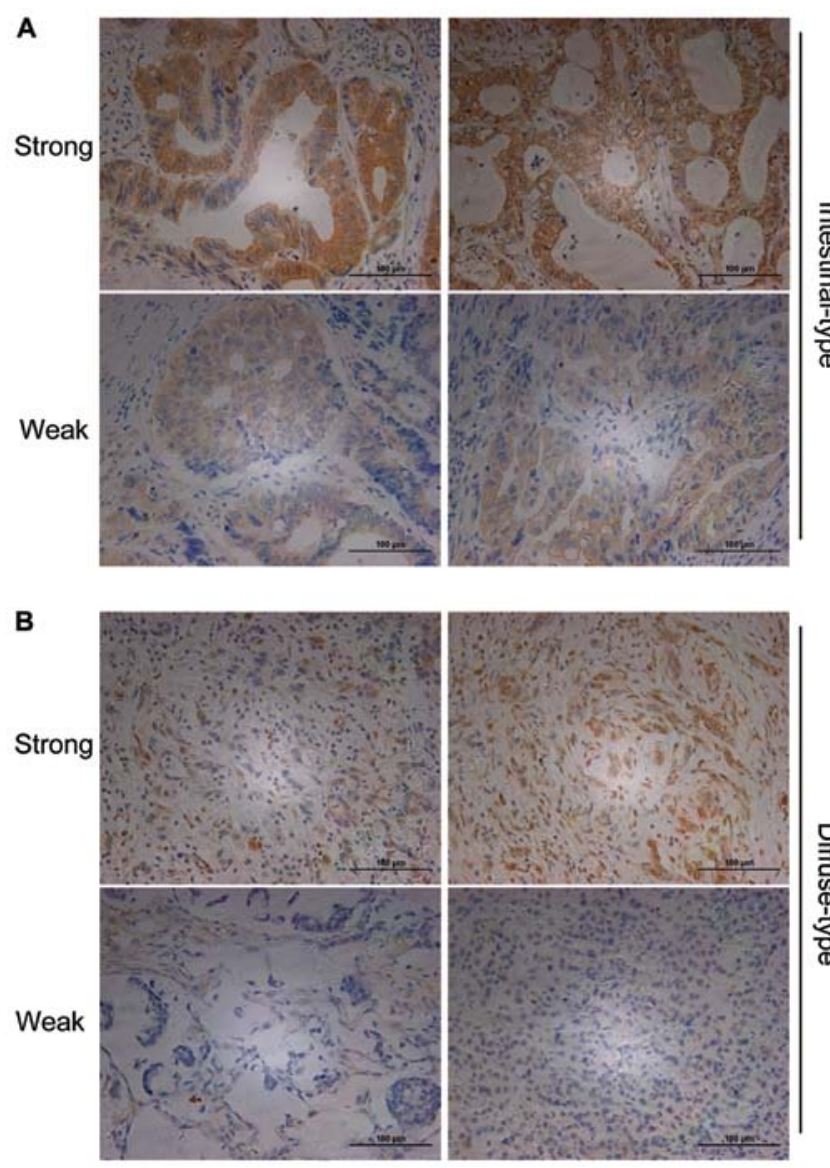

Figure 3. Expression of Slit2 in human gastric cancer tissues. (A) Immunohistochemistry (IHC) staining of Slit2 protein in intestinal-type of gastric cancer tissues. (B) IHC staining of Slit2 protein in diffuse-type of gastric cancer tissues. Original magnification, $\mathrm{x} 200$.

ated gastric carcinoma patients to moderately differentiated and poorly differentiated gastric cancer tissues $(\mathrm{P}=0.005)$. Slit2 levels were higher in intestinal-type gastric cancer than that in diffuse-type gastric cancer $(\mathrm{P}=0.034)$. Higher Slit2 expression levels were correlated with no lymph node metastasis $(\mathrm{P}=0.005)$ and earlier TNM stage (stages I and II) $(\mathrm{P}=0.021)$. Slit2 expression was not significantly affected by age $(\mathrm{P}=0.700)$, gender $(\mathrm{P}=0.761)$, $\mathrm{T}$ stage $(\mathrm{P}=0.717)$ and $\mathrm{M}$ stage $(\mathrm{P}=0.984)$. These data suggested that Slit2 was highly expressed in gastric cancer tissues with less advanced clinicopathological features.

Slit 2 levels are correlated with $\beta$-catenin in gastric cancer tissues. As demonstrated by previous studies, Slit2 regulates the activity of $\beta$-catenin. To investigate the association of Slit2 and $\beta$-catenin, we performed IHC staining using the same cohort of specimens as we used for Slit 2 staining. As expected, we observed the positive correlation between the expression levels of Slit 2 and $\beta$-catenin in gastric cancer analyzed by IHC staining. As shown in Fig. 4A, y-axis represented the IHC scores of $\beta$-catenin and $x$-axis represented the Slit2 IHC scores using the same cohort of gastric cancer specimens. Linear trend line showed Slit2 levels were positively correlated with $\beta$-catenin levels. Pearson correlation analysis showed the correlation coefficient was $0.504(\mathrm{P}<0.001)$.
Table II. Clinicopathologic features of Slit2 in gastric cancer.

\begin{tabular}{|c|c|c|c|}
\hline \multirow[b]{2}{*}{ Features } & \multicolumn{2}{|c|}{ Slit2 } & \multirow[b]{2}{*}{ P-value } \\
\hline & Low $(\%)$ & High (\%) & \\
\hline \multicolumn{4}{|c|}{ Age (years) } \\
\hline$\leq 60$ & $13(46.4)$ & 15 (53.6) & 0.700 \\
\hline$>60$ & $31(50.8)$ & $30(49.2)$ & \\
\hline \multicolumn{4}{|l|}{ Gender } \\
\hline Female & $12(52.2)$ & $11(47.8)$ & 0.761 \\
\hline Male & $32(48.5)$ & $34(51.5)$ & \\
\hline \multicolumn{4}{|c|}{ Differentiation } \\
\hline High & $5(23.8)$ & $16(76.2)$ & 0.005 \\
\hline Median & $10(43.5)$ & $13(56.5)$ & \\
\hline Low & $29(65.9)$ & $15(34.1)$ & \\
\hline \multicolumn{4}{|c|}{ Lauren's classification } \\
\hline Intestinal & $20(39.2)$ & $31(60.8)$ & 0.034 \\
\hline Diffusion & $23(62.2)$ & $14(37.8)$ & \\
\hline \multicolumn{4}{|l|}{ T stage } \\
\hline $\mathrm{T} 1-2$ & $6(54.5)$ & $5(45.5)$ & 0.717 \\
\hline T3-4 & $38(48.7)$ & $40(51.3)$ & \\
\hline \multicolumn{4}{|l|}{$\mathrm{N}$ stage } \\
\hline Negative & $4(21.1)$ & 15 (78.9) & 0.005 \\
\hline Positive & $40(57.1)$ & $30(42.9)$ & \\
\hline \multicolumn{4}{|l|}{ M stage } \\
\hline Negative & $42(48.8)$ & $44(51.2)$ & 0.984 \\
\hline Positive & $2(66.7)$ & $1(33.3)$ & \\
\hline \multicolumn{4}{|l|}{ TNM stage } \\
\hline I-II & $12(34.3)$ & $23(65.7)$ & 0.021 \\
\hline III-IV & $32(59.3)$ & $22(40.7)$ & \\
\hline
\end{tabular}

Table III. Associations of Slit2 and subcellular localization of $\beta$-catenin in gastric cancer.

\begin{tabular}{|c|c|c|c|}
\hline & \multicolumn{2}{|c|}{ Slit2 } & \multirow[b]{2}{*}{ P-value } \\
\hline & Low $(\%)$ & High $(\%)$ & \\
\hline \multicolumn{4}{|c|}{$\beta$-catenin-menbrane } \\
\hline Negative & $37(84.1)$ & $28(62.2)$ & 0.02 \\
\hline Positive & $7(15.9)$ & $17(37.8)$ & \\
\hline \multicolumn{4}{|c|}{$\beta$-catenin-nuclear } \\
\hline Negative & $33(75.0)$ & $42(93.3)$ & 0.011 \\
\hline Positive & $11(27.2)$ & $3(6.7)$ & \\
\hline
\end{tabular}

Moreover, we discovered that Slit2 was correlated with the subcellular location of $\beta$-catenin, which might suggest the activation of $\beta$-catenin related signaling pathway. Among these 89 cases, 24 cases displayed membrane staining of $\beta$-catenin, while 14 cases showed nuclear $\beta$-catenin. As shown in Table III, membrane $\beta$-catenin tended to exist in the high Slit2 expression group (17/24 cases), while nuclear $\beta$-catenin 

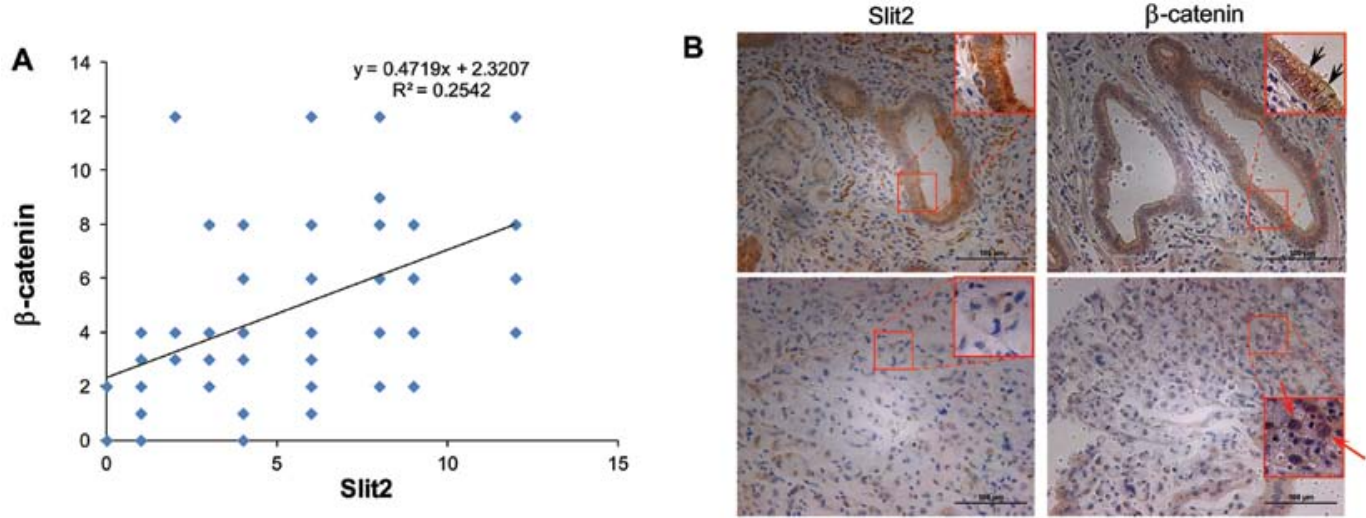

Figure 4. Correlation of Slit2 and $\beta$-catenin in human gastric cancer tissues. (A) The correlation analysis of the immunohistochemistry (IHC) scores of Slit2 and $\beta$-catenin were performed. Scatter plot show the distribution of IHC scores of Slit2 and $\beta$-catenin and linear regression analysis. (B) IHC staining of Slit2 and $\beta$-catenin in the same region of the same cases. Original magnification, $\mathrm{x} 200$.
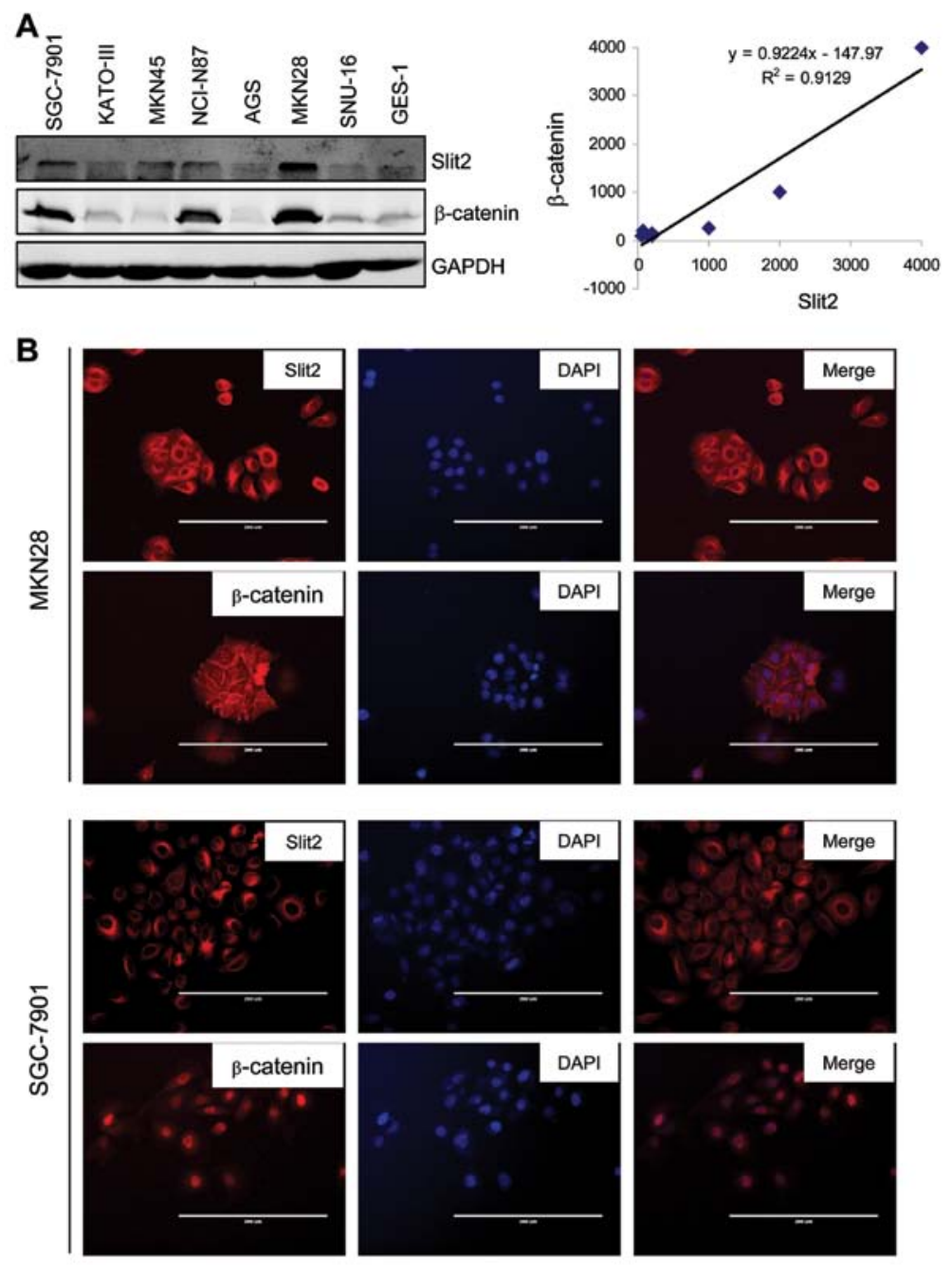

Figure 5. Correlation of Slit2 and $\beta$-catenin in human gastric cancer cell lines. (A) Expression of Slit 2 and $\beta$-catenin in human gastric cancer cell lines and immortalized normal gastric cell line were examined by immunoblotting. The relative density of Slit 2 and $\beta$-catenin in each cell line was used to analyze the correlation coefficient of Slit2 and $\beta$-catenin. Scatter plot shows the distribution of relative density of Slit2 and $\beta$-catenin and linear regression analysis. (B) Immunofluorescence staining of Slit2 and $\beta$-catenin in MKN28 and SGC-7901 gastric cancer cell lines. DAPI was used for nuclear staining. Original magnification, $\mathrm{x} 200$.

tended to exist in the low Slit2 expression group (11/14 cases). As shown in Fig. 4B, strong Slit2 expression was shown in an intestinal-type gastric cancer specimen (upper left), and membrane $\beta$-catenin was also observed in the same case (upper right, black arrows). While the weak Slit2 expression was shown in a diffuse-type gastric cancer specimen (lower 
left), and nuclear $\beta$-catenin translocation was observed in the same case (lower right, red arrows). These data suggested Slit2 expression levels were positively correlated with $\beta$-catenin levels and its subcellular location.

Slit2 levels are correlated with $\beta$-catenin in gastric cancer cell lines. We then examined whether this Slit2- $\beta$-catenin expression pattern could also be observed in human gastric cancer cell lines. To do so, we performed immunoblotting to examine the expression of Slit 2 and $\beta$-catenin using whole cell extracts obtained from seven gastric cancer cell lines and one immortalized normal gastric epithelial cell line, GES-1. Expression of Slit2 protein was also elevated in all 7 gastric cancer cell lines compared with immortalized normal gastric epithelial cell line GES-1 (Fig. 5A, left panel). The levels of $\beta$-catenin were correlated with Slit 2 expression levels. MKN28, a cell line generated from well-differentiated gastric cancer tissue, showed the highest expression levels of Slit2 and $\beta$-catenin. MKN45 and SGC-7901 showed moderate levels of Slit 2 and $\beta$-catenin. The other three cell lines KATO-III, AGS and SNU-16, showed low levels of Slit 2 and $\beta$-catenin. We then performed the semi-quantitative densitometry analysis to calculate relative expression levels of Slit 2 and $\beta$-catenin in each cell line. Levels of Slit 2 and $\beta$-catenin were positively correlated, the correlation coefficient was $0.95(\mathrm{P}<0.001)$. Linear trend line also showed that Slit2 levels were positively correlated with $\beta$-catenin levels (Fig. 5A, right panel).

We next performed immunofluorescence staining to further observe the subcellular location of $\beta$-catenin. We employed MKN28 and SGC-7901 cell lines to perform immunofluorescence staining using anti-Slit 2 and anti- $\beta$-catenin antibodies. As shown in Fig. 4B, MKN28, which highly expressed Slit2, showed the membrane $\beta$-catenin staining. On the contrary, SGC-7901, which expressed lower Slit2 levels compared with MKN28, showed nuclear $\beta$-catenin staining.

\section{Discussion}

Slit2 can positively and negatively regulate tumorigenesis in different types of cancer. To our knowledge, the immunoprofiles of Slit 2 have not previously been studied in gastric cancer. However, a few studies on Slit2 have been performed in gastric cancer. Herein, we examined its expression levels in human gastric cancer tissues and its correlations with clinicopathological characteristics.

Using immunostaining, we showed that Slit2 was negatively or weakly expressed in normal gastric epithelial cells. We also noted that the positive staining of Slit 2 was only observed in cells that located at the neck and bottom part of the glands, which were generally considered as normal gastric stem cells. As indicated in previous findings that Slit2 is involved in gut development (9), Slit2 may also play roles in gastric stem cells, thus explaining why Slit 2 staining was only shown in a specific part of normal gastric glands. Dysplasia and intestinal metaplasia (IM) are two pre-cancerous lesions. Slit2 was expressed in dysplasia and IM glands, suggesting the initiation stage of gastric tumorigenesis might be accompanied by the elevation of Slit 2 expression.

We showed that Slit2 levels were higher in gastric cancer tissues compared with normal gastric cancer tissues. The correlations between Slit2 levels and clinicopathological characteristics suggested gastric patients with high levels of Slit 2 tended to present less advanced cancer features. We also discovered that Slit2 level was high in patients without lymph node metastasis and in early TNM stage. Slit2 was reported to suppress cancer cell growth in colon (14) and breast cancer (19). However, there is no study on the stage-wise correlation pattern of Slit2 in gastric cancer. Our data suggested a correlation of high Slit2 with less malignant features in gastric cancer. Considering the inconsistency between results come from different types of cancer, we concluded that the function of Slit2 in different types of cancer may be different. This phenomenon is common. Other well-studied molecules such as JNK, TGF $\beta 1$, and DDK, play different or even controversial roles in different types of cancer or even in different stages of the same cancer type.

Slit2 can also regulate other signaling pathways. Slit2 can inhibit the AKT-GSK3 $\beta$ signaling pathway $(20,24)$. In the cytoplasm, serine and threonine phosphorylation regulated the stability of $\beta$-catenin by targeting it to GSK-3 $\beta$ /Axin/adenomatous polyposis coli complex-mediated proteasomal degradation. Thus, the destabilization or stabilization of GSK3 $\beta$ activity is a major factor which influences $\beta$-catenin amount and subcellular location. Membrane $\beta$-catenin plays an important role in cadherin-based cell-cell adhesion by indirectly linking cadherins to the actin cytoskeleton. In the nucleus, $\beta$-catenin interacts with members of the LEF/TCF family of transcriptional activators and plays important roles in gastric cancer development and progression. In agreement with previous findings, we show that high Slit2 level is correlated with membrane location of $\beta$-catenin; on the contrary, low Slit2 level can cause nuclear translocation of $\beta$-catenin in gastric cancer specimens and gastric cancer cell lines. Loss of Slit2 expression may stabilize catenin and potentiate its nuclear translocation and thus activate $\beta$-catenin mediated signaling pathway. Our data suggest that Slit 2 is associated with the function of $\beta$-catenin, a cell-cell adhesive molecule or an oncogenic transcriptional factor.

In summary, our study reveal that Slit 2 is highly expressed in human gastric cancer with less advanced clinical features, and Slit2 level is correlated with the expression and the location of $\beta$-catenin. High Slit2 is associated with the integrity of $\beta$-catenin mediated catenin-cadherin cell-cell adhesion. In contrast, low Slit 2 is associated with the activation of $\beta$-catenin mediated signaling pathways. Our data suggest a possible mechanism of the regulation of the subcellular location and activity of $\beta$-catenin by Slit 2 as well as a new role of Slit 2 in gastric cancer development and progression.

\section{Acknowledgements}

The present study is supported by a major program of Minhang District Research Fund.

\section{References}

1. Brenner H, Rothenbacher D and Arndt V: Epidemiology of stomach cancer. Methods Mol Biol 472: 467-477, 2009.

2. Du C, Zhou Y, Cai H, Zhao G, Fu H and Shi YQ: Poor prognostic factors in patients with stage I gastric cancer according to the seventh edition TNM classification: a comparative analysis of three subgroups. J Surg Oncol 105: 323-328, 2012. 
3. Lazar D, Taban S, Sporea I, et al: Gastric cancer: correlation between clinicopathological factors and survival of patients (III). Rom J Morphol Embryol 50: 369-379, 2009.

4. Lazar D, Taban S, Sporea I, et al: Gastric cancer: correlation between clinicopathological factors and survival of patients. II. Rom J Morphol Embryol 50: 185-194, 2009.

5. Macias H, Moran A, Samara Y, et al: SLIT/ROBO1 signaling suppresses mammary branching morphogenesis by limiting basal cell number. Dev Cell 20: 827-840, 2011.

6. Georgas K, Burridge L, Smith K, et al: Assignment of the human slit homologue SLIT2 to human chromosome band 4p15.2. Cytogenet Cell Genet 86: 246-247, 1999.

7. Jia L, Cheng L and Raper J: Slit/Robo signaling is necessary to confine early neural crest cells to the ventral migratory pathway in the trunk. Dev Biol 282: 411-421, 2005.

8. Wong K, Park HT, Wu JY and Rao Y: Slit proteins: molecular guidance cues for cells ranging from neurons to leukocytes. Curr Opin Genet Dev 12: 583-591, 2002.

9. Goldberg D, Borojevic R, Anderson M, Chen JJ, Gershon MD and Ratcliffe EM: Slit/Robo-mediated chemorepulsion of vagal sensory axons in the fetal gut. Dev Dyn 242: 9-15, 2013.

10. Mitra S, Mazumder-Indra D, Mondal RK, et al: Inactivation of SLIT2-ROBO1/2 pathway in premalignant lesions of uterine cervix: clinical and prognostic significances. PLoS One 7: e38342, 2012.

11. Dong R, Yu J,Pu H, Zhang Z and Xu X: Frequent SLIT2 promoter methylation in the serum of patients with ovarian cancer. J Int Med Res 40: 681-686, 2012.

12. Alvarez C, Tapia T, Cornejo V, et al: Silencing of tumor suppressor genes RASSF1A, SLIT2, and WIF1 by promoter hypermethylation in hereditary breast cancer. Mol Carcinog 52: 475-487, 2012

13. Jin J, You H, Yu B, et al: Epigenetic inactivation of SLIT2 in human hepatocellular carcinomas. Biochem Biophys Res Commun 379: 86-91, 2009.

14. Dallol A, Morton D, Maher ER and Latif F: SLIT2 axon guidance molecule is frequently inactivated in colorectal cancer and suppresses growth of colorectal carcinoma cells. Cancer Res 63: 1054-1058, 2003.
15. Dunwell TL, Dickinson RE, Stankovic T, et al: Frequent epigenetic inactivation of the SLIT2 gene in chronic and acute lymphocytic leukemia. Epigenetics 4: 265-269, 2009.

16. Singh RK, Indra D, Mitra S, et al: Deletions in chromosome 4 differentially associated with the development of cervical cancer: evidence of slit 2 as a candidate tumor suppressor gene. Hum Genet 122: 71-81, 2007.

17. Ma S, Liu X, Geng JG and Guo SW: Increased SLIT immunoreactivity as a biomarker for recurrence in endometrial carcinoma. Am J Obstet Gynecol 202: 68.e61-68.e11, 2010.

18. Shen F, Liu X, Geng JG and Guo SW: Increased immunoreactivity to SLIT/ROBO1 in ovarian endometriomas: a likely constituent biomarker for recurrence. Am J Pathol 175: 479-488, 2009.

19. Prasad A, Paruchuri V, Preet A, Latif F and Ganju RK: Slit-2 induces a tumor-suppressive effect by regulating $\beta$-catenin in breast cancer cells. J Biol Chem 283: 26624-26633, 2008.

20. Chen WF, Gao WD, Li QL, Zhou PH, Xu MD and Yao LQ: SLIT2 inhibits cell migration in colorectal cancer through the AKT-GSK3 $\beta$ signaling pathway. Int J Colorectal Dis: Jan 13, 2013 (Epub ahead of print).

21. Liu X, Lu Y, Zhang Y, et al: Slit2 regulates the dispersal of oligodendrocyte precursor cells via Fyn/RhoA signaling. J Biol Chem 287: 17503-17516, 2012

22. Hofmeister W, Devine CA, Rothnagel JA and Key B: Frizzled-3a and slit2 genetically interact to modulate midline axon crossing in the telencephalon. Mech Dev 129: 109-124, 2012.

23. Sinicrope FA, Ruan SB, Cleary KR, Stephens LC, Lee JJ and Levin B: bcl-2 and p53 oncoprotein expression during colorectal tumorigenesis. Cancer Res 55: 237-241, 1995.

24. Chang PH, Hwang-Verslues WW, Chang YC, et al: Activation of Robol signaling of breast cancer cells by Slit 2 from stromal fibroblast restrains tumorigenesis via blocking PI3K/Akt/ $\beta$ catenin pathway. Cancer Res 72: 4652-4661, 2012. 